\title{
Patterns in neurosurgical adverse events: endovascular neurosurgery
}

\author{
Judith M. Wong, M.D., M.P.H., ${ }^{1-3}$ John E. Ziewacz, M.D., M.P.H., ${ }^{4}$ \\ Jaykar R. Panchmatia, M.P.H., M.B.B.ChiR., M.R.C.S., ${ }^{5}$ \\ Angela M. Bader, M.D., M.P.H., ${ }^{1,2,6}$ Aditya S. Pandey, M.D., ${ }^{4}$ \\ B. Gregory Thompson, M.D., ${ }^{4}$ Kai Frerichs, M.D., ${ }^{3}$ \\ and Atul A. Gawande, M.D., M.P.H. ${ }^{1,2,7}$
}

${ }^{1}$ Department of Health Policy and Management, Harvard School of Public Health; ${ }^{2}$ Center for Surgery and Public Health and Departments of ${ }^{3}$ Neurosurgery, ${ }^{6}$ Anesthesiology, Perioperative and Pain Medicine, and ${ }^{7}$ Surgery, Brigham and Women's Hospital, Boston, Massachusetts; ${ }^{4}$ Department of Neurosurgery, University of Michigan Health Systems, Ann Arbor, Michigan; and ${ }^{5}$ Department of Orthopaedics and Trauma, Heatherwood and Wexham Park Hospitals, London, United Kingdom

As part of a project to devise evidence-based safety interventions for specialty surgery, the authors sought to review current evidence in endovascular neurosurgery concerning the frequency of adverse events in practice, their patterns, and current methods of reducing the occurrence of these events. This review represents part of a series of papers written to consolidate information about these events and preventive measures as part of an ongoing effort to ascertain the utility of devising system-wide policies and safety tools to improve neurosurgical practice.

Based on a review of the literature, thromboembolic events appeared to be the most common adverse events in endovascular neurosurgery, with a reported incidence ranging from $2 \%$ to $61 \%$ depending on aneurysm rupture status and mode of detection of the event. Intraprocedural and periprocedural prevention and rescue regimens are advocated to minimize this risk; however, evidence on the optimal use of anticoagulant and antithrombotic agents is limited. Furthermore, it is unknown what proportion of eligible patients receive any prophylactic treatment.

Groin-site hematoma is the most common access-related complication. Data from the cardiac literature indicate an overall incidence of $9 \%$ to $32 \%$, but data specific to neuroendovascular therapy are scant. Manual compression, compression adjuncts, and closure devices are used with varying rates of success, but no standardized protocols have been tested on a broad scale. Contrast-induced nephropathy is one of the more common causes of hospital-acquired renal insufficiency, with an incidence of $30 \%$ in high-risk patients after contrast administration. Evidence from medical fields supports the use of various preventive strategies.

Intraprocedural vessel rupture is infrequent, with the reported incidence ranging from $1 \%$ to $9 \%$, but it is potentially devastating. Improvements in device technology combined with proper endovascular technique play an important role in reducing this risk.

Occasionally, anatomical or technical difficulties preclude treatment of the lesion of interest. Reports of such occurrences are scant, but existing series suggest an incidence of $4 \%$ to $6 \%$. Management strategies for radiation-induced effects are also discussed. The incidence rates are unknown, but protective techniques have been demonstrated.

Many of these complications have strategies that appear effective in reducing their risk of occurrence, but development and evaluation of systematic guidelines and protocols have been widely lacking. Furthermore, there has been little monitoring of levels of adherence to potentially effective practices. Protocols and monitoring programs to support integrated implementation may be broadly effective.

(http://thejns.org/doi/abs/10.3171/2012.7.FOCUS12180)

\section{KEY WORDS • surgical safety - adverse events • perioperative care}

$\mathrm{P}$ ROGRESS in the science of improving surgical safety has been notable in recent years. Methods for evaluating outcomes have been developed and deployed,,$^{10,19,20,31,48,50,81}$ and the resulting data have been used to research patterns of errors and complications. From the

\footnotetext{
Abbreviations used in this paper: $\mathrm{AVM}=$ arteriovenous malformation; CARAT = Cerebral Aneurysm Rerupture After Treatment; $\mathrm{ICP}=$ intracranial pressure.
}

findings, solutions have been designed and tested with sometimes striking improvements, whether based on simple process tools like checklists ${ }^{10,11,26,80}$ or technological changes. ${ }^{22,55,78}$ Neurosurgery is a high-risk surgical specialty that has begun to pursue systematic, nationwide approaches to measuring and improving outcomes. As part of a project funded by the US Agency for Healthcare Research and Quality to devise evidence-based checklists and protocols for specialty surgery, we sought to 
review current evidence in neurosurgery concerning the frequency of adverse events in practice, their patterns, and the state of knowledge about how to improve them. We hypothesized that this consolidation of existing data, even if commonly known to neurosurgeons, will not only highlight the need for devising system-wide policies and safety tools to improve neurosurgical practice but also inform future efforts to develop and implement these tools and policies. We focus this review on complications common to all of endovascular neurosurgery, rather than disease or procedure-specific complications, in an effort to summarize such evidence for potential safety tools in endovascular neurosurgery as a whole.

\section{Scope of the Problem}

Since the advent of the Guglielmi detachable coil in $1991,23,24$ the endovascular treatment of intracranial aneurysms has increased dramatically. From 1998 to 2003,43\% of unruptured and $31 \%$ of ruptured aneurysms were treated endovascularly. ${ }^{7}$ National Inpatient Survey data from 2007 demonstrate that 35,586 aneurysms were treated endovascularly in that year compared with 16,526 in 2003 (http:// hcupnet.ahrq.gov). Neuroendovascular techniques have also expanded to include cranial and spinal AVM embolization, tumor embolization, stroke thrombolysis, vasospasm treatment, and treatment of atherosclerotic disease, among others..$^{56}$

Complications associated with neuroendovascular therapy are common and vary with the rupture status of the lesion being treated. ${ }^{61}$ Overall complication rates are around $20 \%$, with a 1-month mortality rate estimated at $1.4 \% .^{52,61}$ Existent data vary widely in quality, with a substantial amount being from uncontrolled series reported by neurointerventional groups. A few large randomized trials have been conducted specifically within endovascular neurosurgery, but a proportion of what is known regarding interventional angiography is from the cardiac literature. Nonetheless, the most common reported complications within endovascular neurosurgery are thromboembolic events, groin-site hematoma, contrast-induced nephropathy, intraoperative rupture, failure to treat lesion, and radiation-induced effects. Table 1 lists these complications in order of estimated incidence.

\section{Thromboembolic Events}

Thromboembolic events are among the most concerning complications related to endovascular neurosurgery. The incidence is reported to range from $2 \%$ to $61 \%$, depending on rupture status of the treatment target, mode of detection of the event, and type of procedure performed. ${ }^{6,25,45,52,53,58,61,62,66,70,75,79,87}$ Carotid artery stenting tends to be associated with higher intraprocedural thromboembolic rates, with significantly higher risk in patients with symptomatic lesions. Iatrogenic dissection, catheterinduced vasospasm, and operative technique account for most of these events. Patients older than 60 years, those with cerebrovascular disease, and those with longer procedure times are also at greater risk. ${ }^{53}$ Thromboembolic events resulting in persistent neurological deficit occur in
$2 \%-5 \%$ of these patients. ${ }^{18,45,51,62,66}$ Stroke rates at 30 days after stent placement in large trials remain approximately $5 \%$. $^{3,86}$ Ischemic complications during AVM embolization are reported in this section for the sake of completeness, but they represent a category with different causes and management strategies that are beyond the scope of this review, which is intended as groundwork for the design and implementation of broad policies and safety tools for neurosurgery.

\section{Intraprocedural Prevention Strategies}

A variety of rescue therapies have recently been applied when embolism does occur. Intraprocedural administration of abciximab, a glycoprotein IIb-IIIa inhibitor, was used in small uncontrolled series with some good effect. ${ }^{44,58}$ Treatment with another glycoprotein IIb-IIIa inhibitor, tirofiban, has also been reported in uncontrolled series to be safe and effective for dissolving intraprocedural clots. ${ }^{4} \mathrm{~A}$ similarly uncontrolled, but larger, series using intravenous aspirin showed similar results. ${ }^{57}$ Intraprocedural administration of tissue plasminogen activator has been attempted for treatment of thromboembolic consequences, but the limited experience is not supported by any rigorous data. No large randomized studies have been performed to assess the effectiveness and hemorrhagic risk of these agents specifically for neurointerventional cases, and it may be overly difficult to do so.

Air embolism, also a feared complication, deserves mention as there are various preventive strategies that can be employed. For example, formal reconfirmation of an airless flush bag and line system at the beginning of the procedure may be a useful component of an endovascular safety pause. Widespread adherence to these techniques is suspected but has not been formally evaluated.

\section{Periprocedural Prevention Strategies}

Current practice to prevent ischemic complications from thromboembolism may involve use of carefully titrated systemic heparin therapy with varying treatment duration before, during, and after the procedure. . $14,21,33,54,76,85$ Periprocedurally, aspirin and clopidogrel are routinely used for thromboembolism prophylaxis in patients undergoing intra- and extracranial stent placement. . $^{14,16}$ Antiplatelet therapy is used more variably in other procedures, although there is some support in the neurointerventional literature for this approach. Yamada et al.. ${ }^{87}$ in a study of 369 consecutive aneurysm coil embolization cases, retrospectively noted that patients who had been treated preprocedurally with clopidogrel and/ or aspirin had significantly fewer thrombotic complications than those who received antiplatelet therapy only postprocedurally or those who received no antiplatelet therapy (1.9\% vs $2.3 \%$, and $16 \%$, respectively). Any possible benefit of antiplatelet agents in patients with ruptured aneurysms, however, has to be carefully weighed against the risk of hemorrhagic complications related to other procedures, such as ventriculostomies, and the more devastating consequences of intraprocedural rupture or rerupture of the aneurysm prior to its complete repair. The majority of the data supporting combined aspirin/ 


\section{Adverse events in endovascular neurosurgery}

TABLE 1: Frequency of adverse events reported in CSF shunt surgery*

\begin{tabular}{|c|c|c|c|}
\hline AE w/ Authors \& Year & $\begin{array}{l}\text { Sample Size } \\
\text { (no. of pts) }\end{array}$ & Indication & Frequency (\%) \\
\hline \multicolumn{4}{|l|}{ thromboembolic events } \\
\hline Soeda et al., 2003 & 79 & unruptured aneurysm & 61 (22 symptomatic) \\
\hline Timaran et al., 2011 & 40 & PTAS & 50 radiographic (none symptomatic) \\
\hline Qureshi et al., 2000 & 228 & aneurysm w/ parent vessel occlusion & 19 symptomatic \\
\hline Qureshi et al., 2000 & 109 & aneurysm w/ endosaccular occlusion & 11 symptomatic \\
\hline Weber et al., 2007 & 93 & AVM embolization & 9 symptomatic \\
\hline Qureshi et al., 2000 & 834 & PTAS & 9 symptomatic \\
\hline Ries et al., 2009 & 515 & mixed aneurysm & 9 radiographic \\
\hline Pierot et al., 2008 & 739 & unruptured aneurysm & 7 symptomatic \\
\hline Ross \& Dhillon, 2005 & 126 & mixed aneurysm & 9 (6 symptomatic) \\
\hline Qureshi et al., 2000 & 1547 & mixed aneurysm & 8 (5 symptomatic) \\
\hline Van Rooij et al., 2007 & 52 & AVM embolization & 6 symptomatic \\
\hline Coley et al., 2012 & 497 & mixed aneurysm & 5 ruptured, 6 unruptured \\
\hline Qureshi et al., 2000 & 455 & PTA & 5 symptomatic \\
\hline Haw et al., 2006 & 513 & AVM embolization $†$ & 5 symptomatic \\
\hline Saatci et al., 2011 & 350 & AVM embolization† & 4 permanent deficits \\
\hline Yamada et al., 2007 & 369 & unruptured aneurysm & 3 symptomatic \\
\hline Murayama et al., 2003 & 916 & mixed aneurysm & 2 symptomatic \\
\hline \multicolumn{4}{|l|}{ access-related complication } \\
\hline Foran et al., 1993 & 63 & cardiac & 32 \\
\hline Ernst et al., 1993 & 252 & routine cardiac & 21 \\
\hline Sanborn et al., 1993 & 455 & cardiac & 9 \\
\hline Wagenbach et al., 2010 & 295 & mixed intracranial & 1 \\
\hline \multicolumn{4}{|l|}{ contrast-induced nephropathy } \\
\hline Morcos et al., 1999 & NA & NA & $20-30$ (in high-risk pts), $<5$ (in low-risk pts) \\
\hline \multicolumn{4}{|l|}{ intraoperative rupture } \\
\hline Ross \& Dhillon, 2005 & 126 & mixed aneurysm & 9 \\
\hline Coley et al., 2012 & 497 & mixed aneurysm & 6 ruptured, 2 unruptured \\
\hline Elijovich et al., 2008 & 299 & ruptured aneurysm & 5 \\
\hline Li et al., 2006 & 284 & mixed aneurysm & 4 \\
\hline Weber et al., 2007 & 93 & AVM embolization & 4 \\
\hline Loh \& Duckwiler, 2010 & 117 & AVM embolization & 4 \\
\hline Haw et al., 2006 & 513 & AVM embolization & 4 \\
\hline Pierot et al., 2008 & 739 & unruptured aneurysm & 3 \\
\hline Murayama et al., 2003 & 916 & mixed aneurysm & 2 \\
\hline Levy et al., 2001 & 274 & mixed aneurysm & 2 \\
\hline Koebbe et al., 2006 & 1307 & mixed aneurysm & 1 \\
\hline Tummala et al., 2001 & 734 & mixed aneurysm & 1 \\
\hline \multicolumn{4}{|l|}{ failure to treat lesion } \\
\hline Ross \& Dhillon, 2005 & 126 & mixed aneurysm & 6 \\
\hline Murayama et al., 2003 & 916 & mixed aneurysm & 5 \\
\hline Pierot et al., 2008 & 739 & unruptured aneurysm & 4.3 \\
\hline \multicolumn{4}{|l|}{ radiation-induced effects } \\
\hline Saatci et al., 2011 & 350 & AVM embolization & 6 \\
\hline Marti et al., 2008 & 1 & ruptured aneurysm & case report \\
\hline
\end{tabular}

(continued) 
TABLE 1: Frequency of adverse events reported in CSF shunt surgery* (continued)

\begin{tabular}{|c|c|c|c|}
\hline AE w/ Authors \& Year & $\begin{array}{c}\text { Sample Size } \\
\text { (no. of pts) }\end{array}$ & Indication & Frequency (\%) \\
\hline \multicolumn{4}{|c|}{ radiation-induced effects (continued) } \\
\hline D'Incan et al., 2002 & 6 & not reported & small case series \\
\hline Wen at al., 2003 & 1 & unruptured aneurysm & case report \\
\hline
\end{tabular}

clopidogrel therapy is derived from the cardiac literature regarding placement of stents, where large trials have demonstrated a significant impact of dual antiplatelet therapy on the periprocedural prevention of thrombotic complications. ${ }^{34,65}$ Moreover, the combination of aspirin and clopidogrel versus aspirin and ticlodipine was found in a large, randomized trial to be associated with fewer complications (bleeding, neutropenia, thromobocytopenia) and lower rates of discontinuation, while maintaining similar efficacy for patients undergoing cardiac stent placement. $^{2}$

Various intra- and periprocedural prevention and rescue regimens are used to minimize risk for this common but potentially catastrophic complication, but uniform guidelines do not exist. In an extensive review of the prevention and treatment of endovascular procedurerelated thromboembolic complications, Qureshi et al..$^{53}$ make recommendations regarding preventive strategies, stratified by procedure type. However, it remains to be seen how these recommendations, if standardized, will improve practice. An additional preventive measure is further regionalization and mandates for certain levels of technical proficiency and/or volume. These issues are discussed in more detail in the summary paper of this series. ${ }^{84}$

\section{Access-Related Complications}

Groin-site hematoma is the most common puncture site-related complication. Data from the cardiac literature indicate an overall incidence of 9\%-32\%.14,17,64 These figures agree with smaller observational series in elderly patients undergoing neurointerventional procedures. ${ }^{68}$ Wagenbach et al., ${ }^{77}$ in their recent series of almost 300 patients who underwent diagnostic and therapeutic neuroendovascular procedures, report a rate of $1 \%$ even with early ambulation. When severe, groin hematomas require surgical intervention for definitive therapy,,$^{15,46}$ and if left untreated, they may progress to retroperitoneal hematoma, which can be catastrophic. Retroperitoneal hematoma is more frequent in patients requiring aggressive anticoagulation therapy. ${ }^{27,67}$

Measures to minimize the risk of access-related complications include avoiding areas of previous surgery (such as hip replacement or hernia repair) or a lower extremity in which vascular repair has been performed (D.A. Pandey, personal communication, 2010). Classically, manual compression is used to avoid groin-site hematoma and its related complications. Indeed, Wagenbach et al. ${ }^{77}$ prospectively evaluated a protocol encouraging ambulation at 2 hours after a diagnostic or therapeutic cerebral angiogram. Patients were maintained on bed rest for 2 hours after release of manual compression, at which time the site was inspected and palpated. The site was again inspected after an uneventful first ambulation, and if no complications were noted, then the patient was dismissed from the hospital. Five percent of the patients experienced a major or minor complication prior to the 2-hour mark; only 1 patient experienced a major complication after ambulation. Care should be taken to access the femoral artery at a compressible site below the inguinal ligament. ${ }^{56}$ Newer closure devices, including collagen plugs, percutaneous devices, and external compression devices, have been used to help with hemostasis. ${ }^{13}$ Some of these techniques may merely decrease compression time rather than reduce incidence of groin hematomas and can cause significant complications. ${ }^{64}$ Use of these preventive strategies varies among institutions. It remains to be seen whether standardization of one or a combination of these practices could improve hematoma rates.

\section{Contrast-Induced Nephropathy}

Contrast-induced nephropathy is one of the more common causes of hospital-acquired renal insufficiency, with an incidence of less than $5 \%$ in low-risk patients and $20 \%-30 \%$ in high-risk patients after contrast administration. ${ }^{42}$ Risk factors include contrast agents with high osmolar content, ionic contrast agents, and high viscosity; contrast volume; and patient-related factors such as chronic kidney disease, diabetes mellitus, older age, and other cardiovascular risk factors. Preprocedure hydration and administration of n-acetylcysteine or bicarbonate have been proposed as nephroprotective strategies. ${ }^{28,37,47,49}$ The European Society of Urogenital Radiology and the American College of Radiology have established a set of guidelines based on the existing evidence. In the presence of risk factors, alternative imaging techniques should be considered first. If the risks are thought to be outweighed by the benefits of contrast administration, then low-osmolar or iso-osmolar contrast agents are recommended at the minimum required dose. Adequate hydration and/ or additional fluid therapy are also recommended but without clear dosage regimens. Diuretic use is not rec- 
ommended. When possible, nonsteroidal antiinflammatory drugs should be withheld for at least 24 hours before and after the procedure, whereas metformin should be avoided for at least 48 hours before the procedure and until it is clear that contrast-induced nephropathy has not developed after the procedure. There is insufficient data to recommend for or against the use of n-acetylcysteine; thus its use is neither supported nor refuted in the guidelines. ${ }^{1,49,74}$ No prospective, controlled data exist specifically for the neurointerventional field. It is likely that the occurrence of contrast-induced nephropathy is consistent across fields and depends on contrast- and patient-specific factors rather than the underlying indication for imaging or intervention.

\section{Intraoperative Rupture}

Intraprocedural vessel rupture during neuroendovascular procedures is infrequent but potentially devastating. Reports of its incidence range from $1 \%$ to $9 \%$. $^{6,12,25,33,35,36 \text {, }}$ $38,45,52,61,71,79$ Patients who experience intraprocedural rupture during endovascular therapy tend to fare worse than those who experience this complication during open surgery, since the resulting bleeding cannot be immediately decompressed, and all efforts are aimed solely at trying to repair the leakage, potentially even at the cost of vessel sacrifice. The CARAT study of 1010 ruptured intracranial aneurysms treated by coil embolization or clip ligation at 9 high-volume centers in the US found a 5\% risk of intraprocedural rupture in the coil embolization group with an attendant $64 \%$ rate of death or disability, compared with a $31 \%$ rate of death or disability among patients who experienced an intraoperative rupture during open surgical clipping. ${ }^{12}$ Risk factors for intraoperative rupture during occlusion of aneurysms include small aneurysm size, recent rupture, and the presence of a daughter sac..$^{33}$

Rescue therapies in the case of aneurysm rupture consist of continuing with the originally planned coil embolization process, placing coils in the subarachnoid space and retracting them toward the aneurysm dome (to seal it), leaving the microcatheter in place and deploying a second microcatheter, placement of a ventriculostomy, or even vessel sacrifice. ${ }^{33,35}$ Elevated ICP is common following intraprocedural rupture; thus, many authors recommend that supplies for treatment of elevated ICP, including ventriculostomy, be available in the interventional suite in the event of intraprocedural rupture. ${ }^{71}$ Recently at the Mayo clinic, a checklist was developed to help identify and guide emergent management. ${ }^{69}$ Its use and realtime testing for efficacy are highly anticipated.

Vessel rupture during AVM embolization may occur when perforation of a feeding or draining vessel is caused by the microwire or microcatheter. Rescue therapy may consist of immediate injection of embolization material unless the injury is too far upstream. ${ }^{79}$

Improvements in access and embolic devices along with proper endovascular techniques in experienced hands all contribute to minimizing the risk of intraprocedural aneurysm rupture. ${ }^{33}$

\section{Failure to Treat Lesion}

Occasionally, anatomical or technical difficulties preclude treatment of the targeted lesion. Reports of such occurrences are scant, but existing series suggest an incidence of 4\%-6\%.45,52,61 Risk factors include lack of proceduralist experience and lesion locations that are difficult to access. When an endovascular procedure has to be abandoned, alternative methods such as repeat angiography, open surgery, or radiotherapy are considered. Careful analysis of preoperative imaging, including noninvasive and invasive imaging of the access vessels and target lesion, especially with use of postprocessing of images in 3D software, may help to predict and thereby reduce the incidence of "failed" attempts or to prepare for use of assist devices. In the future, preoperative simulation of the anticipated procedure may not only prevent failed attempts, but also allow preparation for the use of the specific devices most likely to succeed in a particular anatomical setting.

\section{Radiation-Induced Effects}

Exposure to ionizing radiation puts patients at risk for both acute and additive effects. The deterministic, or short-term, effects from ionizing radiation involved in continuous imaging are well documented. Skin burns may occur from exposure to radiation doses as low as 2 Gy, while hair loss may occur after $3 \mathrm{~Gy} \cdot{ }^{30}$ Existing data for the risk of stochastic effects such as radiation-induced intracranial neoplasm are largely from children treated for tinea capitis ${ }^{41,59,60,63}$ and patients treated with local and/or whole-brain radiation for neoplastic disease. ${ }^{72}$ The risk for radiation-induced neoplasm is likely dosedependent.$^{59}$ Not only is the patient at risk for harm due to ionizing radiation exposure during these procedures, but the treating physician is also at risk. ${ }^{73}$ Several neurointerventional groups have reported radiation doses delivered to the patient and/or treating physician in single studies or over a hospitalization, $, 8,29,39,43,83$ but no prospective study has been performed to evaluate cause and effect between these exposures and long-term effects such as neoplasm. Techniques to minimize radiation to both patients and their treating physicians include lead shielding, collimation, and minimizing the exposure time and number of runs during angiography. ${ }^{32}$ Adherence to these techniques is not consistently documented.

\section{Conclusions}

Endovascular neurosurgery is a high-risk procedural specialty. For many of the complications discussed in this paper, specific strategies have been demonstrated to be effective in reducing risk, and protocols to support integrated implementation may be broadly effective. Due to the complexity and many inherent differences in the various neurointerventional procedures, such protocols are likely to consist of a basic general set of rules applicable to most or all procedures plus subsets of rules applied to specific procedures. Increased regionalization, more stringent volume requirements, and greater standardiza- 
tion and more rapid assimilation of standardized devices may prove beneficial, particularly for the more technical complications of intraoperative rupture and failure to treat the lesion, but these strategies not been adequately evaluated. These ideas are discussed in more detail in the summary paper of this series. ${ }^{84}$

\section{Disclosure}

This work is funded by a U.S. Agency for Healthcare Quality and Research grant (1R18 HS018537-01). Dr. Gawande receives royalties on his publications and books about patient safety.

Author contributions to the study and manuscript preparation include the following. Conception and design: Gawande, Bader. Acquisition of data: Wong, Ziewacz. Analysis and interpretation of data: Gawande, Wong, Bader. Drafting the article: Wong, Ziewacz, Panchmatia. Critically revising the article: all authors. Reviewed submitted version of manuscript: Gawande, Wong, Bader. Approved the final version of the manuscript on behalf of all authors: Gawande. Study supervision: Gawande, Bader.

\section{References}

1. Barrett BJ, Parfrey PS: Clinical practice. Preventing nephropathy induced by contrast medium. N Engl J Med 354:379386, 2006

2. Bertrand ME, Rupprecht HJ, Urban P, Gershlick AH: Doubleblind study of the safety of clopidogrel with and without a loading dose in combination with aspirin compared with ticlopidine in combination with aspirin after coronary stenting: the clopidogrel aspirin stent international cooperative study (CLASSICS). Circulation 102:624-629, 2000

3. Brott TG, Hobson RW II, Howard G, Roubin GS, Clark WM, Brooks W, et al: Stenting versus endarterectomy for treatment of carotid-artery stenosis. N Engl J Med 363:11-23, 2010

4. Bruening R, Mueller-Schunk S, Morhard D, Seelos KC, Brueckmann H, Schmid-Elsaesser R, et al: Intraprocedural thrombus formation during coil placement in ruptured intracranial aneurysms: treatment with systemic application of the glycoprotein IIb/IIIa antagonist tirofiban. AJNR Am J Neuroradiol 27:1326-1331, 2006

5. Byrne JV, Molyneux AJ, Brennan RP, Renowden SA: Embolisation of recently ruptured intracranial aneurysms. J Neurol Neurosurg Psychiatry 59:616-620, 1995

6. Coley S, Sneade M, Clarke A, Mehta Z, Kallmes D, Cekirge $\mathrm{S}$, et al: Cerecyte coil trial: procedural safety and clinical outcomes in patients with ruptured and unruptured intracranial aneurysms. AJNR Am J Neuroradiol 33:474-480, 2012

7. Cowan JA Jr, Ziewacz J, Dimick JB, Upchurch GR Jr, Thompson BG: Use of endovascular coil embolization and surgical clip occlusion for cerebral artery aneurysms. J Neurosurg 107:530-535, 2007

8. D'Ercole L, Mantovani L, Thyrion FZ, Bocchiola M, Azzaretti A, Di Maria F, et al: A study on maximum skin dose in cerebral embolization procedures. AJNR Am J Neuroradiol 28:503-507, 2007

9. D'Incan M, Roger H, Gabrillargues J, Mansard S, Parent S, Chazal J, et al: [Radiation-induced temporary hair loss after endovascular embolization of the cerebral arteries: six cases.] Ann Dermatol Venereol 129:703-706, 2002 (Fr)

10. de Vries EN, Hollmann MW, Smorenburg SM, Gouma DJ, Boermeester MA: Development and validation of the SURgical PAtient Safety System (SURPASS) checklist. Qual Saf Health Care 18:121-126, 2009

11. de Vries EN, Prins HA, Crolla RM, den Outer AJ, van Andel G, van Helden SH, et al: Effect of a comprehensive surgical safety system on patient outcomes. N Engl J Med 363:19281937,2010
12. Elijovich L, Higashida RT, Lawton MT, Duckwiler G, Giannotta S, Johnston SC: Predictors and outcomes of intraprocedural rupture in patients treated for ruptured intracranial aneurysms: the CARAT study. Stroke 39:1501-1506, 2008

13. Ernst SM, Tjonjoegin RM, Schräder R, Kaltenbach M, Sigwart U, Sanborn TA, et al: Immediate sealing of arterial puncture sites after cardiac catheterization and coronary angioplasty using a biodegradable collagen plug: results of an international registry. J Am Coll Cardiol 21:851-855, 1993

14. Fiehler J, Ries T: Prevention and treatment of thromboembolism during endovascular aneurysm therapy. Klin Neuroradiol 19:73-81, 2009

15. Filis K, Arhontovasilis F, Theodorou D, Albanopoulos K, Lagoudianakis E, Manouras A, et al: Management of early and late detected vascular complications following femoral arterial puncture for cardiac catheterization. Hellenic J Cardiol 48:134-142, 2007

16. Fiorella D: Anti-thrombotic medications for the neurointerventionist: aspirin and clopidogrel. J Neurointerv Surg 2:44-49, 2010

17. Foran JP, Patel D, Brookes J, Wainwright RJ: Early mobilisation after percutaneous cardiac catheterisation using collagen plug (VasoSeal) haemostasis. Br Heart J 69:424-429, 1993

18. Gallas S, Pasco A, Cottier JP, Gabrillargues J, Drouineau J, Cognard C, et al: A multicenter study of 705 ruptured intracranial aneurysms treated with Guglielmi detachable coils. AJNR Am J Neuroradiol 26:1723-1731, 2005

19. Gawande AA, Studdert DM, Orav EJ, Brennan TA, Zinner MJ: Risk factors for retained instruments and sponges after surgery. N Engl J Med 348:229-235, 2003

20. Gawande AA, Thomas EJ, Zinner MJ, Brennan TA: The incidence and nature of surgical adverse events in Colorado and Utah in 1992. Surgery 126:66-75, 1999

21. Gonzalez N, Murayama Y, Nien YL, Martin N, Frazee J, Duckwiler G, et al: Treatment of unruptured aneurysms with GDCs: clinical experience with 247 aneurysms. AJNR Am J Neuroradiol 25:577-583, 2004

22. Greenberg CC, Diaz-Flores R, Lipsitz SR, Regenbogen SE, Mulholland L, Mearn F, et al: Bar-coding surgical sponges to improve safety: a randomized controlled trial. Ann Surg 247:612-616, 2008

23. Guglielmi G, Viñuela F, Dion J, Duckwiler G: Electrothrombosis of saccular aneurysms via endovascular approach. Part 2: Preliminary clinical experience. J Neurosurg 75:8-14, 1991

24. Guglielmi G, Viñuela F, Sepetka I, Macellari V: Electrothrombosis of saccular aneurysms via endovascular approach. Part 1: Electrochemical basis, technique, and experimental results. J Neurosurg 75:1-7, 1991

25. Haw CS, terBrugge K, Willinsky R, Tomlinson G: Complications of embolization of arteriovenous malformations of the brain. J Neurosurg 104:226-232, 2006

26. Haynes AB, Weiser TG, Berry WR, Lipsitz SR, Breizat AH, Dellinger EP, et al: A surgical safety checklist to reduce morbidity and mortality in a global population. N Engl J Med 360:491-499, 2009

27. Johnson LW, Esente P, Giambartolomei A, Grant WD, Loin M, Reger MJ, et al: Peripheral vascular complications of coronary angioplasty by the femoral and brachial techniques. Cathet Cardiovasc Diagn 31:165-172, 1994

28. Kelly AM, Dwamena B, Cronin P, Bernstein SJ, Carlos RC: Meta-analysis: effectiveness of drugs for preventing contrastinduced nephropathy. Ann Intern Med 148:284-294, 2008

29. Kemerink GJ, Frantzen MJ, Oei K, Sluzewski M, van Rooij WJ, Wilmink J, et al: Patient and occupational dose in neurointerventional procedures. Neuroradiology 44:522-528, 2002

30. Ketteler ER, Brown KR: Radiation exposure in endovascular procedures. J Vasc Surg 53 (1 Suppl):35S-38S, 2011

31. Khuri SF, Daley J, Henderson W, Hur K, Demakis J, Aust JB, 
et al: The Department of Veterans Affairs' NSQIP: the first national, validated, outcome-based, risk-adjusted, and peercontrolled program for the measurement and enhancement of the quality of surgical care. Ann Surg 228:491-507, 1998

32. Kim KP, Miller DL: Minimising radiation exposure to physicians performing fluoroscopically guided cardiac catheterisation procedures: a review. Radiat Prot Dosimetry 133:227233, 2009

33. Koebbe CJ, Veznedaroglu E, Jabbour P, Rosenwasser RH: Endovascular management of intracranial aneurysms: current experience and future advances. Neurosurgery 59 (5 Suppl 3): S93-S113, 2006

34. Leon MB, Baim DS, Popma JJ, Gordon PC, Cutlip DE, Ho $\mathrm{KK}$, et al: A clinical trial comparing three antithromboticdrug regimens after coronary-artery stenting. N Engl J Med 339:1665-1671, 1998

35. Levy E, Koebbe CJ, Horowitz MB, Jungreis CA, Pride GL, Dutton K, et al: Rupture of intracranial aneurysms during endovascular coiling: management and outcomes. Neurosurgery 49:807-813, 2001

36. Li MH, Gao BL, Fang C, Cheng YS, Li YD, Wang J, et al: Prevention and management of intraprocedural rupture of intracranial aneurysm with detachable coils during embolization. Neuroradiology 48:907-915, 2006

37. Lin J, Bonventre JV: Prevention of radiocontrast nephropathy. Curr Opin Nephrol Hypertens 14:105-110, 2005

38. Loh Y, Duckwiler GR: A prospective, multicenter, randomized trial of the Onyx liquid embolic system and N-butyl cyanoacrylate embolization of cerebral arteriovenous malformations. Clinical article. J Neurosurg 113:733-741, 2010

39. Mamourian AC, Young H, Stiefel MF: Cumulative radiation dose in patients admitted with subarachnoid hemorrhage: a prospective study using a self-developing film badge. AJNR Am J Neuroradiol 31:1787-1790, 2010

40. Marti N, Lopez V, Pereda C, Martin JM, Montesinos E, Jorda E: Radiation-induced temporary alopecia after embolization of cerebral aneurysms. Dermatol Online J 14:19, 2008

41. Modan B, Baidatz D, Mart H, Steinitz R, Levin SG: Radiationinduced head and neck tumours. Lancet 1:277-279, 1974

42. Morcos SK, Thomsen HS, Webb JA: Contrast-media-induced nephrotoxicity: a consensus report. Contrast Media Safety Committee, European Society of Urogenital Radiology (ESUR). Eur Radiol 9:1602-1613, 1999

43. Moskowitz SI, Davros WJ, Kelly ME, Fiorella D, Rasmussen PA, Masaryk TJ: Cumulative radiation dose during hospitalization for aneurysmal subarachnoid hemorrhage. AJNR Am J Neuroradiol 31:1377-1382, 2010

44. Mounayer C, Piotin M, Baldi S, Spelle L, Moret J: Intraarterial administration of Abciximab for thromboembolic events occurring during aneurysm coil placement. AJNR Am J Neuroradiol 24:2039-2043, 2003

45. Murayama Y, Nien YL, Duckwiler G, Gobin YP, Jahan R, Frazee J, et al: Guglielmi detachable coil embolization of cerebral aneurysms: 11 years' experience. J Neurosurg 98: 959-966, 2003

46. Nasser TK, Mohler ER III, Wilensky RL, Hathaway DR: Peripheral vascular complications following coronary interventional procedures. Clin Cardiol 18:609-614, 1995

47. Navaneethan SD, Singh S, Appasamy S, Wing RE, Sehgal AR: Sodium bicarbonate therapy for prevention of contrastinduced nephropathy: a systematic review and meta-analysis. Am J Kidney Dis 53:617-627, 2009

48. Neily J, Mills PD, Young-Xu Y, Carney BT, West P, Berger $\mathrm{DH}$, et al: Association between implementation of a medical team training program and surgical mortality. JAMA 304: 1693-1700, 2010

49. Pannu N, Wiebe N, Tonelli M: Prophylaxis strategies for contrast-induced nephropathy. JAMA 295:2765-2779, 2006

50. Paull DE, Mazzia LM, Wood SD, Theis MS, Robinson LD,
Carney B, et al: Briefing guide study: preoperative briefing and postoperative debriefing checklists in the Veterans Health Administration medical team training program. Am J Surg 200:620-623, 2010

51. Pelz DM, Lownie SP, Fox AJ: Thromboembolic events associated with the treatment of cerebral aneurysms with Guglielmi detachable coils. AJNR Am J Neuroradiol 19:1541-1547, 1998

52. Pierot L, Spelle L, Vitry F: Immediate clinical outcome of patients harboring unruptured intracranial aneurysms treated by endovascular approach: results of the ATENA study. Stroke 39:2497-2504, 2008

53. Qureshi AI, Luft AR, Sharma M, Guterman LR, Hopkins LN: Prevention and treatment of thromboembolic and ischemic complications associated with endovascular procedures: Part II-Clinical aspects and recommendations. Neurosurgery 46:1360-1376, 2000

54. Qureshi AI, Suri MF, Sung GY, Straw RN, Yahia AM, Saad $M$, et al: Prognostic significance of hypernatremia and hyponatremia among patients with aneurysmal subarachnoid hemorrhage. Neurosurgery 50:749-756, 2002

55. Regenbogen SE, Greenberg CC, Resch SC, Kollengode A, Cima RR, Zinner MJ, et al: Prevention of retained surgical sponges: a decision-analytic model predicting relative costeffectiveness. Surgery 145:527-535, 2009

56. Rengachary SS, Ellenbogen RG (eds): Principles of Neurosurgery, ed 2. Edinburgh: Elsevier Mosby, 2005

57. Ries T, Buhk JH, Kucinski T, Goebell E, Grzyska U, Zeumer $\mathrm{H}$, et al: Intravenous administration of acetylsalicylic acid during endovascular treatment of cerebral aneurysms reduces the rate of thromboembolic events. Stroke 37:1816-1821, 2006

58. Ries T, Siemonsen S, Grzyska U, Zeumer H, Fiehler J: Abciximab is a safe rescue therapy in thromboembolic events complicating cerebral aneurysm coil embolization: single center experience in 42 cases and review of the literature. Stroke 40:1750-1757, 2009

59. Ron E, Modan B, Boice JD Jr, Alfandary E, Stovall M, Chetrit A, et al: Tumors of the brain and nervous system after radiotherapy in childhood. N Engl J Med 319:1033-1039, 1988

60. Ron E, Modan B, Preston D, Alfandary E, Stovall M, Boice JD Jr: Radiation-induced skin carcinomas of the head and neck. Radiat Res 125:318-325, 1991

61. Ross IB, Dhillon GS: Complications of endovascular treatment of cerebral aneurysms. Surg Neurol 64:12-19, 2005

62. Saatci I, Geyik S, Yavuz K, Cekirge HS: Endovascular treatment of brain arteriovenous malformations with prolonged intranidal Onyx injection technique: long-term results in 350 consecutive patients with completed endovascular treatment course. Clinical article. J Neurosurg 115:78-88, 2011

63. Sadetzki S, Chetrit A, Freedman L, Stovall M, Modan B, Novikov I: Long-term follow-up for brain tumor development after childhood exposure to ionizing radiation for tinea capitis. Radiat Res 163:424-432, 2005

64. Sanborn TA, Gibbs HH, Brinker JA, Knopf WD, Kosinski EJ, Roubin GS: A multicenter randomized trial comparing a percutaneous collagen hemostasis device with conventional manual compression after diagnostic angiography and angioplasty. J Am Coll Cardiol 22:1273-1279, 1993

65. Schömig A, Neumann FJ, Kastrati A, Schühlen H, Blasini R, Hadamitzky M, et al: A randomized comparison of antiplatelet and anticoagulant therapy after the placement of coronaryartery stents. N Engl J Med 334:1084-1089, 1996

66. Soeda A, Sakai N, Sakai H, Iihara K, Yamada N, Imakita $\mathrm{S}$, et al: Thromboembolic events associated with Guglielmi detachable coil embolization of asymptomatic cerebral aneurysms: evaluation of 66 consecutive cases with use of diffusion-weighted MR imaging. AJNR Am J Neuroradiol 24:127-132, 2003

67. Sreeram S, Lumsden AB, Miller JS, Salam AA, Dodson TF, 
Smith RB: Retroperitoneal hematoma following femoral arterial catheterization: a serious and often fatal complication. Am Surg 59:94-98, 1993

68. Stiefel MF, Park MS, McDougall CG, Albuquerque FC: Endovascular treatment of unruptured intracranial aneurysms in the elderly: analysis of procedure related complications. J Neurointerv Surg 2:11-15, 2010

69. Taussky P, Lanzino G, Cloft H, Kallmes D: A checklist in the event of aneurysm perforation during coiling. AJNR Am J Neuroradiol 31:E59, 2010 (Letter)

70. Timaran CH, Rosero EB, Higuera A, Ilarraza A, Modrall JG, Clagett GP: Randomized clinical trial of open-cell vs closedcell stents for carotid stenting and effects of stent design on cerebral embolization. J Vasc Surg 54:1310-1316, 2011

71. Tummala RP, Chu RM, Madison MT, Myers M, Tubman D, Nussbaum ES: Outcomes after aneurysm rupture during endovascular coil embolization. Neurosurgery 49:1059-1067, 2001

72. Umansky F, Shoshan Y, Rosenthal G, Fraifeld S, Spektor S: Radiation-induced meningioma. Neurosurg Focus 24(5):E7, 2008

73. Valentin J: Avoidance of radiation injuries from medical interventional procedures. Ann ICRP 30:7-67, 2000

74. Van Praet JT, De Vriese AS: Prevention of contrast-induced nephropathy: a critical review. Curr Opin Nephrol Hypertens 16:336-347, 2007

75. van Rooij WJ, Sluzewski M, Beute GN: Brain AVM embolization with Onyx. AJNR Am J Neuroradiol 28:172-178, 2007

76. Vance AZ, Jayaraman MV, Dubel GJ, Doberstein CE, Haas RA: Safety of intravenous heparin administration after endovascular treatment for ruptured intracranial aneurysms. J Neurointerv Surg 1:136-141, 2009

77. Wagenbach A, Saladino A, Daugherty WP, Cloft HJ, Kallmes DF, Lanzino G: Safety of early ambulation after diagnostic and therapeutic neuroendovascular procedures without use of closure devices. Neurosurgery 66:493-497, 2010

78. Walker IA, Merry AF, Wilson IH, McHugh GA, O’Sullivan E, Thoms GM, et al: Global oximetry: an international anaesthesia quality improvement project. Anaesthesia 64:1051-1060, 2009

79. Weber W, Kis B, Siekmann R, Kuehne D: Endovascular treatment of intracranial arteriovenous malformations with onyx: technical aspects. AJNR Am J Neuroradiol 28:371-377, 2007

80. Weiser TG, Haynes AB, Dziekan G, Berry WR, Lipsitz SR,
Gawande AA: Effect of a 19-item surgical safety checklist during urgent operations in a global patient population. Ann Surg 251:976-980, 2010

81. Weiser TG, Makary MA, Haynes AB, Dziekan G, Berry WR, Gawande AA: Standardised metrics for global surgical surveillance. Lancet 374:1113-1117, 2009

82. Wen CS, Lin SM, Chen Y, Chen JC, Wang YH, Tseng SH: Radiation-induced temporary alopecia after embolization of cerebral arteriovenous malformations. Clin Neurol Neurosurg 105:215-217, 2003

83. White PM, Gilmour JN, Weir NW, Innes B, Sellar RJ: AngioCT in the management of neurointerventional patients: a prospective, consecutive series with associated dosimetry and resolution data. Neuroradiology 50:321-330, 2008

84. Wong JM, Bader AM, Laws ER, Popp AJ, Gawande AA: Patterns in neurosurgical adverse events and proposed strategies for reduction. Neurosurg Focus 33(5):E1, 2012

85. Workman MJ, Cloft HJ, Tong FC, Dion JE, Jensen ME, Marx WF, et al: Thrombus formation at the neck of cerebral aneurysms during treatment with Guglielmi detachable coils. AJNR Am J Neuroradiol 23:1568-1576, 2002

86. Yadav JS, Wholey MH, Kuntz RE, Fayad P, Katzen BT, Mishkel GJ, et al: Protected carotid-artery stenting versus endarterectomy in high-risk patients. N Engl J Med 351:1493-1501, 2004

87. Yamada NK, Cross DT III, Pilgram TK, Moran CJ, Derdeyn CP, Dacey RG Jr: Effect of antiplatelet therapy on thromboembolic complications of elective coil embolization of cerebral aneurysms. AJNR Am J Neuroradiol 28:1778-1782, 2007

Manuscript submitted May 14, 2012.

Accepted July 6, 2012.

Portions of this work were presented in oral abstract form at the New England Neurosurgical Society annual meeting in Chatham Bars, Massachusetts, in June 2011.

Please include this information when citing this paper: DOI: 10.3171/2012.7.FOCUS12180.

Address correspondence to: Atul A. Gawande, M.D., M.P.H., Department of Surgery, Brigham and Women's Hospital, 75 Francis Street, Boston, Massachusetts 02115. email: agawande@partners. org. 